\title{
Introduction of the American Pediatric Society's 2009 John Howland Award Recipient, Jerold F. Lucey, M.D.
}

\author{
LEWIS R. FIRST \\ Department of Pediatrics, University of Vermont College of Medicine, Burlington, Vermont 05405
}

$\mathrm{T}$ Thank you Dr. Lister, Colleagues, and Friends of the Pediatric Academic Societies. I am delighted and honored to be able to introduce Dr. Jerold F. Lucey as the 2009 recipient of the John Howland Award for distinguished contributions that have aided in the advancement of our field of Pediatrics and in turn have improved the health of infants and children in this country and around the world.

Over the next several minutes-I would like to help you.

$L$ - ook at Jerry's early years and how they began to shape his career

$U$-nderstand how and why he became a neonatologist

$C$-elebrate his contributions to neonatology

$E$-laborate on his role as an educator and editor and help all of you

$Y$ - earn to make a difference in the lives of children like Jerry has

Jerry Lucey (Fig. 1A) was born in Holyoke, MA and spent most of his youth growing up in Northampton, MA. Although his parents and grandparents, who raised him, were not physicians, at the age of $6 \mathrm{y}$, he remembers his initial interest in medicine began with helping people, who were sick, get better (1). He was also greatly influenced by his local primary care physician in Northampton, who encouraged him to consider persuing a career in medicine.

In high school, Jerry kept his medical aspirations on a back burner while he was elected president of his senior class, played varsity football for $2 \mathrm{y}$, and participated in drama club. Pursuit of a medical career was postponed again when he enlisted in the Navy, shortly before World War 2 ended. Officer Lucey, Seaman First Class, was sent out to sea on a ship destined for China. For a variety of reasons, the ship never made it to China. Jerry lost 40 pounds on that trip, and discovered that a career at sea was not for him due to problems with seasickness.

On returning home, Jerry completed his undergraduate studies at Dartmouth with a major in zoology (Fig. 1B) and was accepted and enrolled in the New York University Col-

Received July 10, 2009; accepted August 23, 2009.

Correspondence: Lewis R. First, M.D., Department of Pediatrics, University of Vermont College of Medicine, E203 Given Building, 89 Beaumont Avenue, Burlington, VT 05405; e-mail: Lewis.First@uvm.edu

Presented at the 2009 Annual Meeting of the Pediatric Academic Societies, Baltimore, MD. lege of Medicine. During medical school, Jerry joined the laboratory of Henry Barnett, a noted pediatrician at Cornell, where he studied renal clearance rates of breast milk and formula compared with adults. As part of the experiment, Jerry volunteered to drink infant formula for three days and was pleased to learn he could concentrate his urine better than a premature infant. According to Jerry, this experience in clinical investigation played a key role in his decision to stay in academic medicine, and more importantly, to focus his efforts on improving the health of premature infants.

At the conclusion of medical school, Jerry embarked on an internship at Bellevue Hospital in New York City and then went on to do his pediatric residency at ColumbiaPresbyterian Medical Center (1953-1955). During his residency, he worked with Dr. William Silverman on a randomized trial of different antibiotics in the prevention of newborn infections. While working on this project, Jerry discovered that babies treated with sulfa drugs experienced kernicterus. This incidental finding taught Jerry the importance of doing well-run clinical trials and ignited his passion for studying the metabolism of bilirubin and ways to prevent kernicterus.

After residency, Jerry did a research fellowship under the mentorship of Dr. Clement Smith, recipient of the Howland Award in 1976, at Harvard and Children's Hospital Boston. There he discovered the remarkable world of the Gunn rat, a rodent that can become highly jaundiced and develop kernicterus due to its lack of the enzyme UDP glucoronyltransferase.

In 1956, Jerry accepted a faculty position in Vermont from Dr. Jim McKay, despite Charles Janeway's (Physician-inChief at Boston Children's and recipient of the Howland Award in 1978) admonition that "You go to Vermont and you will bury yourself and never be heard of ever again" (1). I guess that was not true for Jerry, just as it was not true for Jim, or me. In fact, Boston tried to recruit Jerry on several occasions, but Vermont countered and as Jim McKay writes in a letter to a friend discussing Jerry's decision to stay in Vermont, "while the Boston position was a very desirable one, we promoted him to Associate Professor at a salary of \$12,000 a year, so our University obviously thinks as highly of him as I do" (personal correspondence).

Perhaps, Jerry's most famous contribution to kernicterus research began in the late 1960s, when he read a small case 

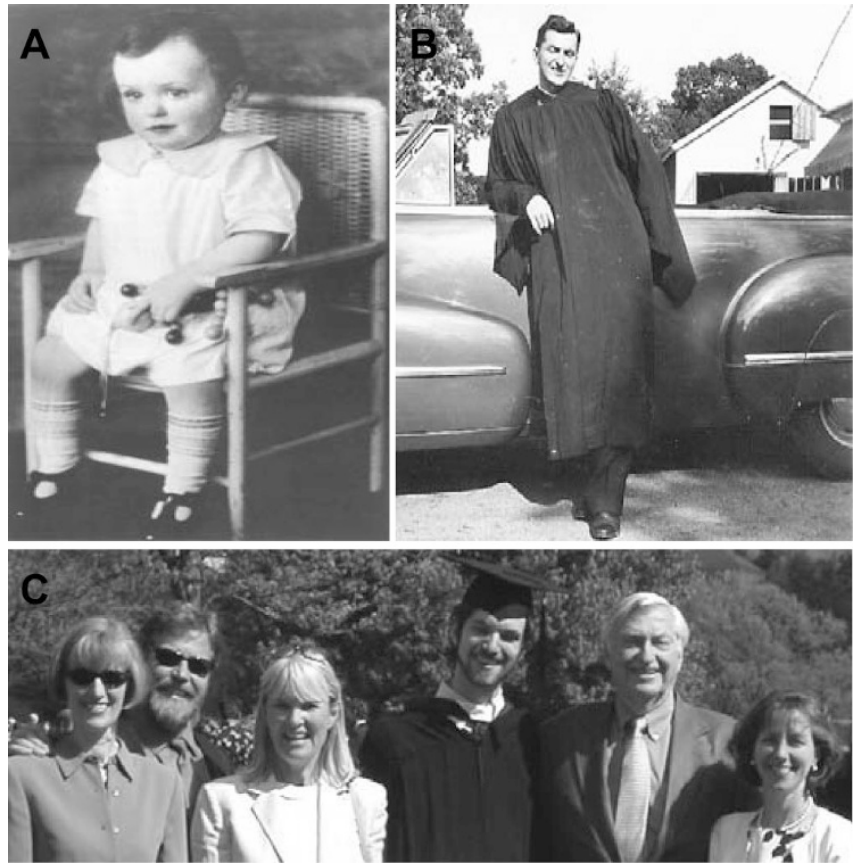

Figure 1. $A$, Jerry Lucey as a toddler. $B$, Jerry as a college graduate. $C$, The Lucey family: from left to right daughter Colleen, son David, wife Ingela, son Patrick, Jerry, and daughter Kate.

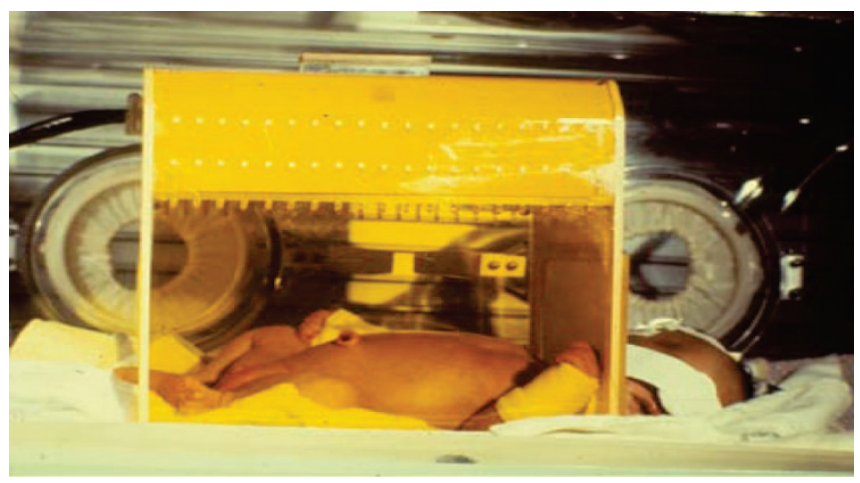

Figure 2. The first set of phototherapy lights used in Vermont.

series published in the Lancet, which described nine babies in Great Britain treated with phototherapy for newborn jaundice (2). Jerry set up the first randomized controlled trial of phototherapy in this country, described the success of this therapy, and as a result popularized its use, so that it is now accepted worldwide. Jerry's use of the randomized controlled trial with Dr. Silverman, and later as an independent investigator, was one of the first applications of this technique in clinical research, and as a result, the randomized controlled trial has become the gold standard, on which so many discoveries in pediatrics, as well as medicine, have been established. Jerry received numerous awards for this work and discovered a type of transient familial hyperbilirubinemia that bears his name, but most notably, he developed the first set of "bili lights" (Fig. 2) used in this country to provide phototherapy to infants. This device is now part of the Smithsonian Institute's collection of historical medical devices in Washington DC.

Jerry did not stop his exploration of neonatal physiology with his work on bilirubin. While in Germany in the mid 1970s, Jerry learned about trancutaneous oxygen and carbon dioxide monitoring of blood gases. He brought the monitor back to the United States and set up randomized trials, which established this mode of noninvasive monitoring as standard of care in this country and the world.

A third example of his use of a randomized control trial involved the use of artificial surfactant. Jerry ran this trial in eight hospitals in Europe, 16 in the United States, and revolutionized the care of premature lung disease with this artificial replacement therapy, resulting in significant drops in the death rate of premature infants by more than $30 \%$.

Recognizing the importance of collaboration to improve outcomes after a sabbatical at Oxford, Jerry established an international network of NICUs to improve quality of care and to be settings for further randomized controlled trials, and thus the Vermont Oxford Neonatal Network (VON) was born. Initially, 30 hospitals were brought together, and thanks to a generous grant from the Ronald McDonald Research Foundation, these 30 have grown into more than 850 NICUs worldwide. VON currently handles data on over 50,000 infants less than $1500 \mathrm{~g}$. All the projects that VON takes on are designed to improve quality of care and reduce the morbidity and mortality in babies. The collaborative efforts between VON NICUs have resulted in more than 90 publications to date, making VON a world recognized leader in the field of evidence-based medicine in neonatology.

In addition to his numerous professional accomplishments, Jerry is also a consummate educator and teacher as demonstrated by his more than 160 articles, 6 edited books, multiple chapters in 11 different texts, several films and videos, and two exceptional CME courses-one for general pediatricians and another exclusively for neonatologists, which is viewed as, not just the largest, but the best course of its kind. But perhaps, Jerry's role as educator is best exemplified by his $35 \mathrm{y}$ tenure as editor-in-chief of the journal, Pediatrics. Under his leadership, the journal has undergone an extraordinary period of growth and development, and thanks to the creativity, energy, dedication, and the fairness Jerry has shown in his quest to make the journal the premier publication in our field.

Needless to say, in the midst of all these accomplishments, there have been many other remarkable career milestones for Jerry-winning the AAP's Virginia Apgar Award and Medical Education Award, induction into the Institute of Medicine of the National Academy of Sciences, a Lifetime Achievement Award from the Vermont Medical Society, receipt of the Alfred I. DuPont Award for Excellence in Children's Health Care, being named the Harry Wallace Professor of Neonatology, and in turn having an endowed chair in Neonatology named in his honor. But perhaps, the most unique highlight occurred when Jerry almost attained knighthood by being awarded honorary membership in the World Society of Pediatrics and Child Health in York, England. Her Royal Highness, Princess Anne, presented the award to Jerry, who is only the eighth American to receive this honor, as a tribute to his outstanding achievements in pediatric care, education, and research.

Aside from his professional accomplishments in academic medicine as scientist, physician, and educator, Jerry is a 
consummate family man-husband to his wonderful wife Ingela, father to Patrick Colleen, David, and Kate (Fig. 2), grandfather to four grandchildren-Molly, Chloe, Ben, and Sam, and great grandfather to Nikhil.

Forgive me if I get a bit personal for a moment, but I need to also express my own gratitude to Jerry. There is no way I would have left Children's Hospital Boston in 1994 and ended up in Vermont if Jerry had not had taken the risk to recommend me to the search committee. So, thank you Jerry from the bottom of my heart for opening opportunities for me, as you have done for so many others, and for being not only a mentor, but better yet, a true friend for the decade and a half we have known each other.

This is what Jerry Lucey is all about-someone, who during the more than $55 \mathrm{y}$ of his professional career, sees what others cannot and in doing so invests the time, the energy, and the dedication to make the outcome even better for all parties concerned. Thus, as a true tribute to Jerry Lucey as a scientist, investigator teacher, editor, mentor, advisor, friend, visionary, father, and spouse, we gather today not only to honor him with this award but for all of us to say what is really the bottom line of this introduction-we love Lucey!
Jerry, you have meant and continue to mean so much to so many including the thousands of pediatricians, nurses, trainees, and most importantly patients and families, who are grateful for the multitude of remarkable contributions you have made to child health.

To wrap up this introduction,

$L$-et's stand

$U-\mathrm{p}$ and

$C$-heer for someone who has done

$E$ - xtraordinary work on behalf of children and families and whose contributions will make a difference for

$Y$ - ears to come!

Ladies and Gentlemen, I give you the 2009 winner of the John Howland Award-Dr. Jerold F. Lucey!

\section{REFERENCES}

1. Lucey JF. 2009 Oral history interview of Jerold F. Lucey, M.D., interviewed by Lawrence M. Gartner, M.D., October 10, 2002, Burlington, Vermont. Elk Grove Village, IL: American Academy of Pediatrics

2. Lucey JF 1960 Hyperbilirubinemia of Prematurity. Pediatrics 25:690-710 